\title{
Somatotropic Effects of Exogenous Prolactin and Growth Hormone in Juvenile Lizards (Lacerta s. sicula)
}

\author{
PAUL LICHT AND HERMIEN HOYER \\ Department of Zoology, University of California, Berkeley, California, and \\ Zoological Laboratory. State University of Utrecht, the Netherlands
}

Received February 18, 1968

\begin{abstract}
The somatotropic effects of ovine prolactin and bovine growth hormone (GH) were compared in juveniles of the lizard Lacerta sicula sicula. Both hormones stimulated a marked increase (up to $300 \%$ ) in food consumption. This effect was associated with a pronounced increase in weight gain which involved some fattening and considerable linear growth: the rclativc amount of lcan growth and fattcning were the same with both hormones. GH was slightly more potent on a weight basis, but both were highly effective at a dose of $10 \mu \mathrm{g} /$ day and some response was evideul between 1 and $50 \mu \mathrm{g} /$ day.

Total lipid storage was the same under both hormone treatments but lipid distributions in the body differed, especially with regard to the liver. GH promoted splanchnomegaly and lipid storage in the liver whereas prolactin decreased hepatic growth and lipid content. When the two hormones were given together, there was no synergism or additive effect with respect to total growth and the effects of prolactin on the liver were antagonized by the $\mathrm{GH}$.
\end{abstract}

Recent studies with ovine prolactin in adult male Anolis carolinensis (Family Iguanidae) suggest that prolactin may be an important somatotropic hormone in lizards. For example, the administration of ovine prolactin in Anolis may stimulate appetite, increase linear growth, enhance tail regeneration (Licht and Jones, 1967; Licht, 1967), and increase the frequency of skin sloughing (Maderson and Licht, 1967). Mammalian growth hormone $(\mathrm{GH})$ has also been shown to increase growth rates in lizards-in juveniles of $A$. carolinensis-but the details of its actions were not reported (DiMaggio, 1960).

A comparison of the somatotropic actions of prolactin and $\mathrm{GH}$ and information on their effects in other reptilian species are clearly needed before their relative importance in the physiology of hiese vertebrates can be evaluated. In an attempt to provide such data, we examined the effects of exogenous prolactin and $\mathrm{GH}$ in juvenile male and female Lacerta sicula (Family Lacertidae).

\section{MATERIALS AND METHODS}

Hormones. The hormones used in this study were provided by the Endocrinology Study Section of the National Institutes of Health. GII was of bovine origin (NIH B-8) and assayed as having a mean potency of $0.8 \mathrm{IU} / \mathrm{mg}$ based on the growlh of hypophysectomized female rats. The prolactin activity of this preparation, based on the pigeon crop bioassay, was reported to be approximately $1 \mathrm{IU} / \mathrm{mg}$. The prolactin preparation was of ovine origin (NIH PS-7) and assayed at a mean potency of $25 \mathrm{IU} / \mathrm{mg}$. The GH contamination was reported as $0.0039 \mathrm{IU} / \mathrm{mg}$. The hormones were dissolved in $0.01 \mathrm{~N} \mathrm{NaOH}$ and injected subcutaneously, in the neck region, in $0.02 \mathrm{ml}$ of solution. All injections were given in the morning; i.e., within 2 hours of the time the lights went on.

Injections consisted of: (1) ovine prolactin; (2) bovine $\mathrm{GH}$; (3) a combination of prolactin and $\mathrm{GH}$; or (4) $0.01 \mathrm{~N} \mathrm{NaOH}$ (controls). During the first 40 days, animals received $1 \mu \mathrm{g}$ 
hormone daily. This dosage was found to be only slightly effective, and consequently was increased to $10 \mu \mathrm{g}$ daily after 40 days. GH remained at this level for the remainder of the experiment, but prolactin was increased to $50 \mu \mathrm{g}$ daily 2 weeks later. In combination, the dosages were adjusted to equal the doses of GH and prolactin being used at the same time and always in a volume of $0.02 \mathrm{ml}$ solution.

Lizards. Sixty Lacerta were collected in the vicinity of Naples, Italy in mid-July. They were kept in the laboratory in Utrecht until the start of hormone treatment about 2 weeks later. On August 3 , they were divided randomly into 4 groups of 15 (they could not be sexed accurately at this time). Each group was placed in an aquarium, heated and lighted by $75-\mathrm{W}$ incandescent lamp for 8 hours daily. The lizards generally regulated body temperature between $32^{\circ}$ and $36^{\circ} \mathrm{C}$ (their preferred temperature range) while the lights were on; the minimal temperature available in each cage was $30-31^{\circ} \mathrm{C}$ during this period. The lizards were at room temperature, 22 $25^{\circ} \mathrm{C}$ during the remaining 16 hours daily.

During the first 3 wecks of treatment the lizards were fed mealworms and fiy maggots ad libitum. Measurements of food consumption (appetite) were begun during the fourth week. At this time, the number of maggots was limited to about 1 per animal per day and only mealworms (averaging $125 \mathrm{mg}$ each) were offered ad libitum. In this way, the food consumption of the various groups could be compared on the basis of the number of mealworms taken. In fact, the groups eating the fewest mealworms also tended to take fewer maggots; thus, the comparisons in appetite reported here are conservative estimates of the differences among groups. All lizards were given water ad libitum; a commercial pet vitamin mixture was given once a week.

Lizards were weighed every 8-10 days; food was withheld for 36 hours prior to weighing to allow the gut to be cleared. Linear growth was estimated by measuring the snout-vent (sv) length.

After approximately 90 days, the animals were autopsied to determine the nature of the ohserved changes in body weight. Animals were killed by decapitation. Measurements were made of the fresh wet weight of the liver and abdominal fat bodies-the two major discrete sites of lipid storage in the lizard. These organs and the carcass were dried to constant weight at $60^{\circ} \mathrm{C}$, and their lipid contents determined by extracting lipids with a mixture of methanol, chloroform, and ether in equal proportions. In the carcass, lipids appeared to be concentrated to some extent in the ventral part of the neck and at the base of the tail. At autopsy animals were sexed and the gonads weighed and examined histologically.

Although the life history of $L$. sicula is not well known, the lizards used here were probably about 1 year old. They averaged between 3.3 and $3.6 \mathrm{~g}$ and $56-57 \mathrm{~mm}$ at the start of treatment (Table 1). One female laid an egg in captivity, in the first week of observation, but most of the animals appeared to be sexually immature. Both sexes would probably have reached sexual maturity during the next summer. Newly hatched $L$. sicula are about $25 \mathrm{~mm}$ in $\mathrm{sv}$ length and weigh less than $1 \mathrm{~g}$. Large adult females may reach $75 \mathrm{~mm}$ and $10 \mathrm{~g}$ when fat; males tend to be slightly larger. Thus, the animals used here were of about $\%$ the adult length and $1 / 3$ the adult weight.

\section{RESULTS}

Reproductive system. At the time of autopsy, most individuals in each group were found to be females. Since there was little difference in response between the two sexes, the data were pooled. The ovaries were small and contained only immature ova in all cases. The testes were somewhat enlarged, averaging $14 \mathrm{mg}$ as compared with $2-5 \mathrm{mg}$ when fully regressed; they showed considerable spermatogenic activity, with abundant spermatids, but the epididymis was still atrophic. Gonads were similar among the four groups.

Body growth. All of the lizards gained weight during the 3 -month observation period and all except a few controls increased measurably in snout-vent length. The mean weight gains and linear changes for the four groups are summarized in Figs. 1 and 2 and Table 1.

Mean body weights increased steadily during the first 40 days (Fig. 1). Growth rates of prolactin-treated animals $(1 \mu \mathrm{g} /$ day) were identical to those of the controls, but both groups receiving $\mathrm{GH}(1 \mu \mathrm{g})$ day) gained significantly more weight during this period $(p<.05)$. When measurements of food consumption (Fig. 3) were begun after 29 days it was found that all three hormone-treated groups were eating approximatcly cqual amounts but averag- 


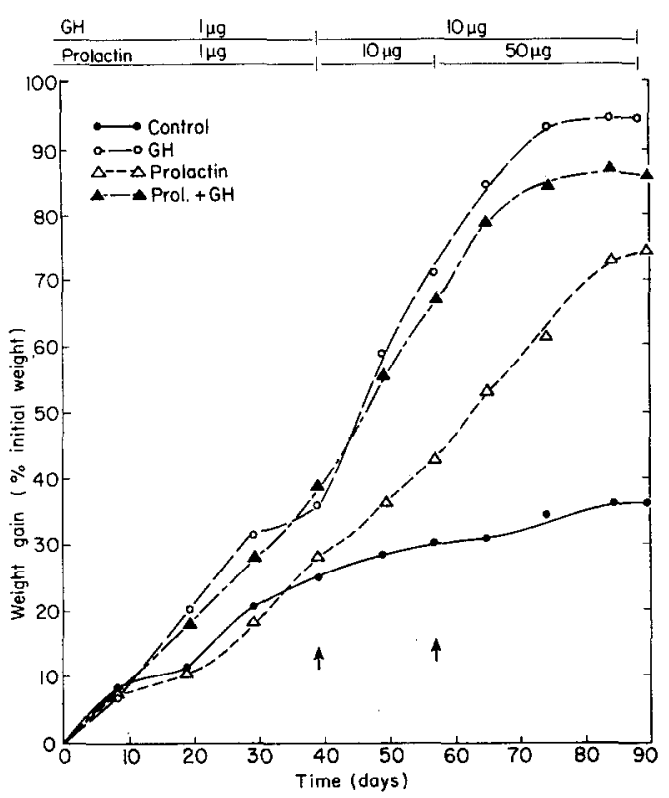

FIG. 1. Changes in body weight in juvenile Lacerta sicula during 84-90 days of treatment. Changes are expressed in relation to the mean initial body weights for each group. Curves connect the mean values for the 12-15 individuals in each group. Changes in daily dosages of each hormone are shown at the top and by arrows; in combination, the dosage of each was always equivalent to the separate treatments.

ing about $35 \%$ more intake than controls.

The controls grew only slowly after 40 days, after body weight increased about $25 \%$ over initial values. In contrast, all hormone-treated animals, now receiving $\mathbf{1 0}$ $\mu \mathrm{g} / \mathrm{day}$, continued to grow at the high initial rate and their body size diverged progressively from that of the controls. This continued high weight gain was as-

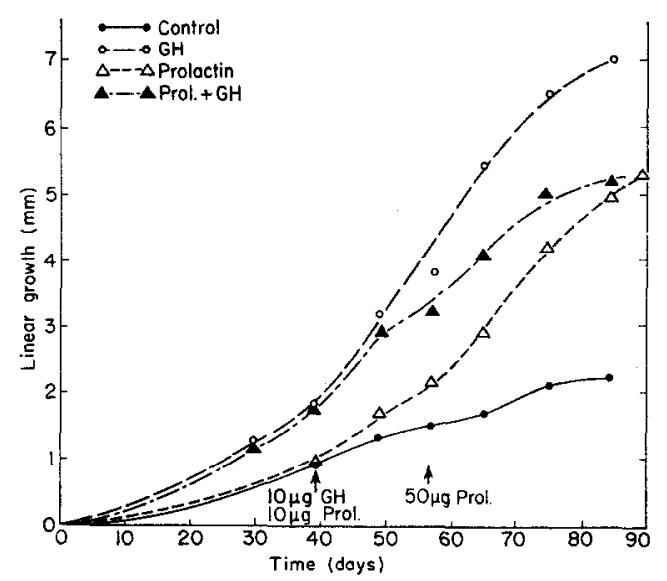

FIt. 2. Linear growth measured as changes in snout-vent length in juvenile Lacerta sicula. Data correspond to those for body weights shown in Fig. 1. Arrows indicate when hormone dosages were increased as indicated in Fig. 1.

sociated with a further increase in food consumption. The hormone-treated groups were eventually eating two to three times more than controls (Fig. 3 ).

Growth rates and appetite were similar among the animals receiving $\mathrm{GH}$ and $\mathrm{GH}$ plus prolactin. Both groups tended to grow faster than those receiving only prolactin when the $10 \mu \mathrm{g} /$ day dosage was used. When the dosage of prolactin was increased to $50 \mu \mathrm{g} /$ day -after 57 days-their rates of food consumption and growth increased slightly and were equivalent to those of the GH-treated animals receiving $10 \mu \mathrm{g} /$ day. At the time of autopsy, after 90 days of treatment, there were no significant differences in the mean total weight gains among the three hormone-

TABLE 1

Influence of Prolactin and GH on Growth in Juventle Lacerta sicula

\begin{tabular}{|c|c|c|c|c|c|c|c|c|c|c|}
\hline \multirow[b]{2}{*}{ Treatment } & \multirow[b]{2}{*}{$\mathrm{N}^{a}$} & \multicolumn{3}{|c|}{ Body weight (g) } & \multicolumn{3}{|c|}{ Snout-vent length (mm) } & \multicolumn{2}{|c|}{$\begin{array}{c}\text { Body } \\
\text { proportions } \\
(\mathrm{g} / \mathrm{mm})\end{array}$} & \multirow{2}{*}{$\begin{array}{l}\text { Growth } \\
(\mathrm{mm} / \mathrm{g})\end{array}$} \\
\hline & & Initial & Final & Change $^{b}$ & Initial & Final & Change $^{b}$ & Initial & Final & \\
\hline Control & 15 & 3.63 & 4.90 & $1.27 \pm 0.12$ & 56.9 & 59.0 & $2.2 \pm 0.33$ & .064 & .083 & 1.73 \\
\hline Prolactin & 14 & 3.47 & 6.04 & $2.57 \pm 0.25^{c}$ & 57.4 & 62.7 & $5.3 \pm 0.41^{c}$ & .061 & .096 & 2.06 \\
\hline $\mathrm{GH}$ & 13 & 3.30 & 6.40 & $3.10 \pm 0.25^{c}$ & 56.0 & 62.9 & $6.9 \pm 0.76^{r}$ & 059 & .101 & 2.22 \\
\hline Prolactin + GH & 12 & 3.45 & 6.25 & $2.80 \pm 0.32^{c}$ & 56.8 & 61.9 & $5.1 \pm 0.51^{c}$ & .061 & .100 & 1.82 \\
\hline
\end{tabular}

a All groups started with 15 individuals; reductions are due to some mortality and escapes.

${ }^{b}$ Mean \pm standard error.

${ }^{c}$ Differ significantly from respective values for controls $(p<.01)$. 


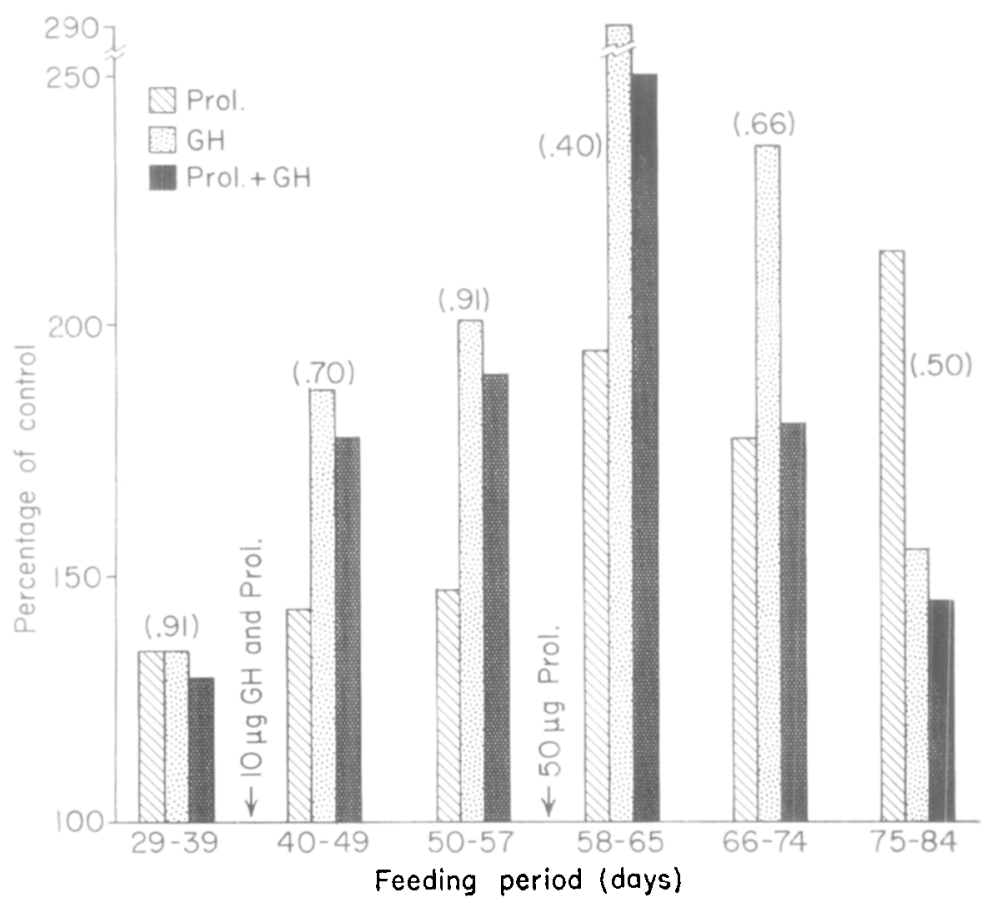

FIG. 3. Effects of hormone treatment on food consumption in juvenile Lacerta sicula. Vertical bars show the mean food consumption of 12-14 individuals in each hormone-treated group in relation to the mena food consumption of the $\mathbf{1 5}$ control animals during the same period. The actual amount of food eaten by controls expressed as mealworms eaten per animal per day for each period is shown in the parentheses over each set of bars. Arrows indicate the times when hormone dosages were increased, starting with $1 \mu \mathrm{g} / \mathrm{day}$, as indicated in Fig. 1.

treated groups (Table 1) $(p>.10)$, and all gains were markedly greater than in the controls $(p<.001)$.

Changes in sv length (linear growth) paralleled those in body weight (Fig. 2), except that differences between the GHtreated groups and other groups werc not significant until after 50 days. The magnitude of the total growth during the 3 months of treatment is illustrated in Fig. 4.

Some insight into the effects of the hormones on growth patterns can be gained by examining the relative linear and weight changes (Table 1). The increase in ratios of weight to length from initial levels of $0.06 \mathrm{~g} / \mathrm{mm}$ to $0.08-0.10 \mathrm{~g} / \mathrm{mm}$ and the general appearance of the animals at the end of the experiment (Fig. 4) suggest that all were fattening. The larger final ratio of weight to length in hormonetreated animals suggests a tendency toward proportionally more fattening than in controls. Although differences in these proportions were not significant $(p>.05)$, data on lipid contents (below) support this conclusion.

The relations between linear growth and the total weight gain $(\Delta \mathrm{mm} / \Delta \mathrm{gm}) \mathrm{did}$ not differ significantly among the four groups, indicating that prolactin and growth hormone influenced the rate of growth more than the pattern of growth. This similarity in growth patterns is even more striking if the four groups are compared when reaching comparable levels of weight gain. For example, the GH-treated animals gained approximately $36 \%$ in weight $(1.2 \mathrm{~g})$ at 35 days when they had grown $1.8 \mathrm{~mm}-1.5 \mathrm{~mm} / \mathrm{g}$-whereas, the controls at the end of 88 days had gained about $36 \%$ in weight $(1 / 31 \mathrm{~g})$ and grown $2.3 \mathrm{~mm}-1.75 \mathrm{~mm} / \mathrm{g}$.

Organ compositions. The weights of the liver and abdominal fat bodies and lipid contents in various compartments of the 

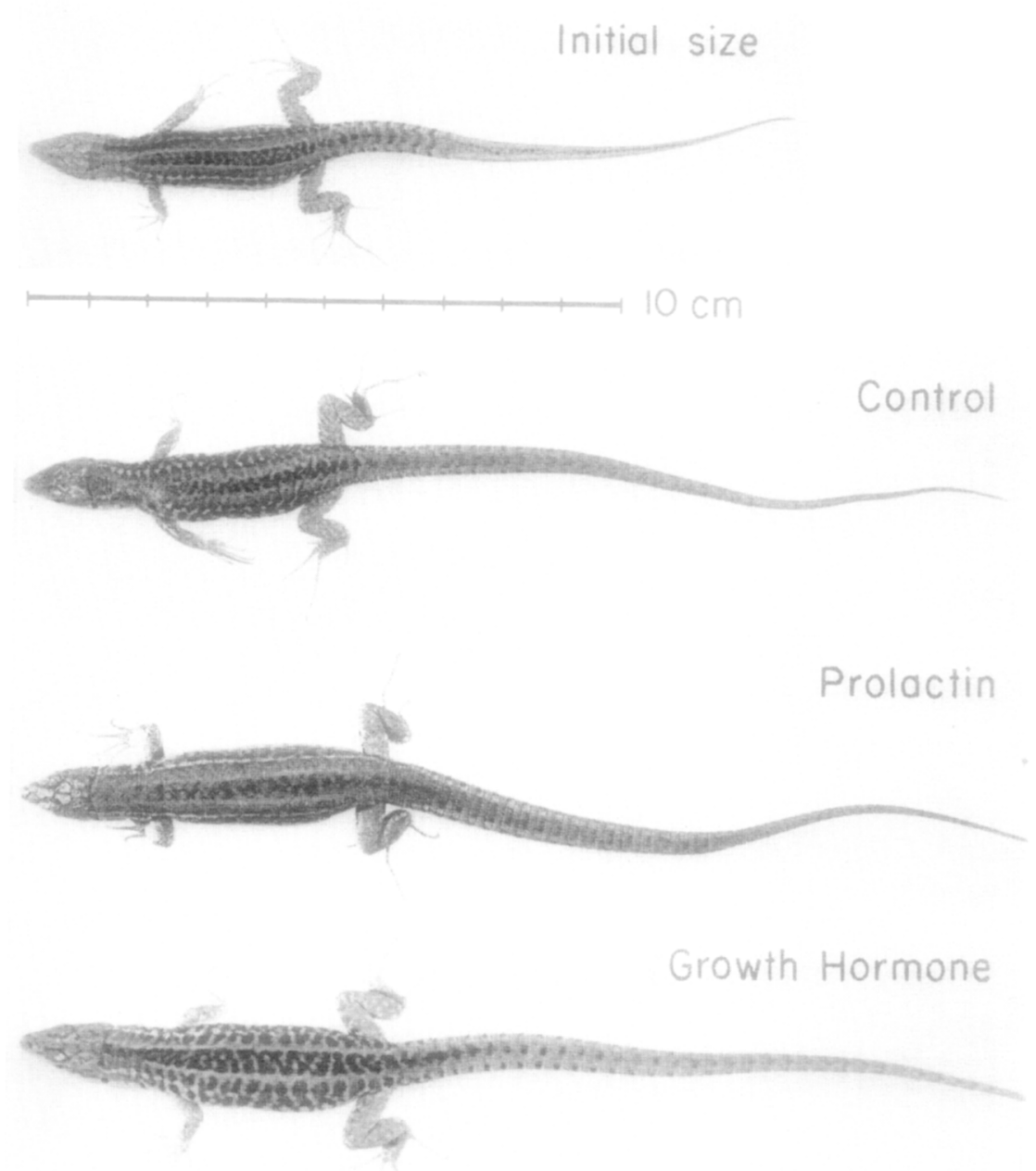

FIG. 4. Comparison of the growth-promoting actions of prolactin and GH in juvenile Lacerta sicula. The animals shown were chosen to illustrate the average sv length and body weight for various treatments. The initial size at the start of the experiment is shown on the top. The lower three individuals represent the final size after 3 months of treatment as indicaled. Color patterns were highly variable and differences evident in this figure are not intended to indicate differences among groups.

body are summarized in Table 2 . Tack of information on the condition of these organs at the beginning of the experiment hinders analysis of growth. As indicated above, the change in the body dimensions suggests that all groups fattened to some extent.

A portion of the additional weight gains in the hormone-treated animals clearly involved lipid storage. Comparisons of total lipid fractions (mg lipid/g body weight) also indicates that these groups tended to become proportionally fatter than controls (Table 2). While the total lipid storage was the same in prolactin- and GH-treated groups, there was a pronounecd difference in the distribution of lipid, particularly with respect to the liver.

In the GH-treated animals, total weight gains involved an increase in liver weight, fat body weight, carcass lipids, and linear growth, as already discussed. The enlargement of the liver was due to a doubling of both lipid content and lean dry weight. 


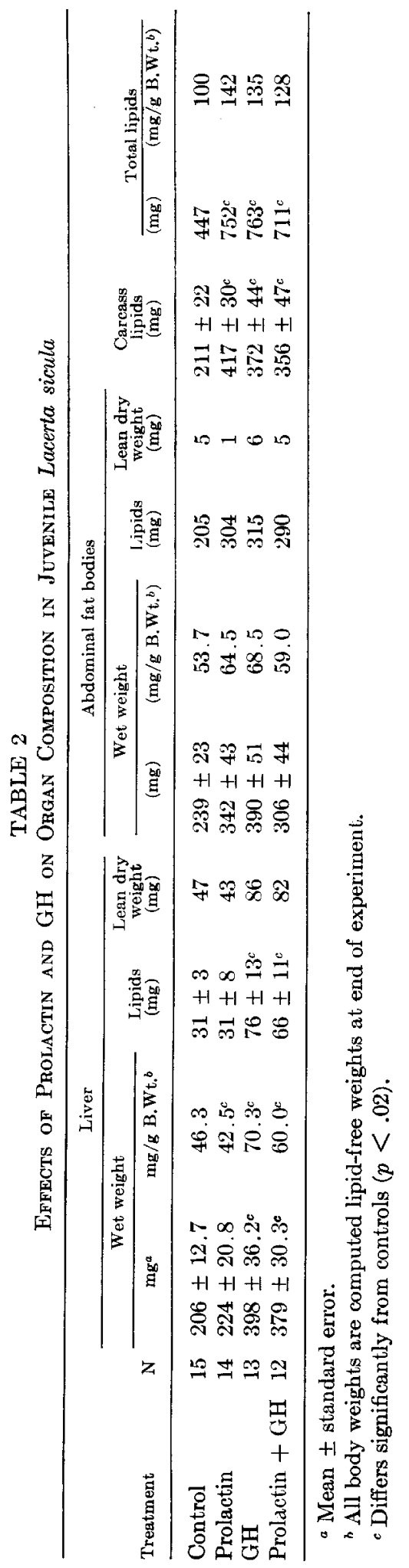


The latter fraction presumably represents glycogen and protein increases (it is probably largely protein since glycogen concentrations are usually relatively low). The total growth of the liver in GHtreated animals may be viewed as an aspect of splanchnomegaly since the liver became proportionally larger than in controls (see $\mathrm{mg}$ liver $/ \mathrm{g}$ body weight in Table 2).

In contrast, the liver of the prolactintreated animals was almost identical in size and composition to the controls even though the former gained twice as much in total body weight (Table 1): this disproportionately small hepatic growth is also reflected in the significantly reduced ratio of liver weight to total body weight in prolactin-treated animals (Table 2). Thus, prolactin significantly decreased both the growth rate and lipid storage in the liver. A slightly greater lipid storage in other carcass depots (excluding the abdominal fat bodies) apparently accompanied the reduced hepatic lipid storage in these animals (see last three columns of Table 2).

Despite the marked differenecs in total liver weights among the four groups, the composition of this organ with respect to the fractions of water, lipid, and lean (protein?) dry weight were similar in all groups averaging $62 \%, 15 \%$, and $23 \%$, respectively. Thus, both liver (proteinaceous) growth and lipid storage were apparently equally stimulated by GII and equally inhibited by prolactin; i.e., neither hormone differentially influenced one of these aspects of liver function.

\section{DISCUSSION}

Both ovine prolactin and bovine growth hormone have pronounced somatotropic effects in the juvenile lizard. In evaluating the details of their actions, it is necessary to recognize the potential interaction with endogenous hormones, since the lizards' own pituitaries were intact. Relatively high growth rates among the controls presumably reflect high levels of endogenous somatotropic hormones, and it is not surprising that the effects of cxogcnous hor- mones were most distinct when growth rates among controls were lowest.

In general, the primary action of both prolactin and $\mathrm{GH}$ appeared to be the stimulation of appetite (hyperphagia). The markedly divergent growth rates among control and hormone-treated animals resulting from this augmentation of appetite hinders evaluation of the metabolic actions of the hormones, especially since the measurement of sv length is a relatively insensitive estimate of lean growth (i.e., protein synthesis). Ideally, animals should all be hypophysectomized and/or maintained on an isocaloric diet, but the juvenile lizards were not amenable to the necessary hand feeding (see Licht, 1967).

These restrictions notwithstanding, the growth promoted by the two hormones appeared to be similar, involving an extension of the general growth pattern observed in the controls; i.e., the relative proportions of linear growth and fattening were similar among prolactin-treated, GHtreated, and control animals. These results are in contrast to those obtained with adult male Anolis in which prolactin caused a significant increase in the relative proportion of linear growth (Licht, 1967). This diserepancy between adults and juveniles is not surprising since the adults normally grow only very slowly in length, tending only to fatten on a high caloric intake. The adults presumably have lower levels (or a lower sensitivity to) endogenous somatotropic hormones than do the juveniles.

Although the general proportion of linear growth and fattening promoted by prolactin and $\mathrm{GH}$ was similar, the two hormones in Lacerta sicula were clearly distinct with regard to their effects on the liver. In GH-treated animals, the relation between hepatic growth and lipid storage and total body growth were similar to the pattern observed in controls. However, in prolactin-treated animals, there was a significant reduction in both aspects of hepatic response. When the two hormones are given in combination, only the effects of $\mathrm{GH}$ are evident with regard to the liver. The extent to which this depressing effect 
on liver growth and lipid storage is a general action of prolactin in reptiles remains to be determined. However, it is noteworthy that ovine prolactin had the same effect on liver metabolism in adult male Anolis representing a different age, sex, and farnily of lizards (see Fig. 4 in Licht, 1967). Thus, this action of prolactin may well be of general importance among lizards.

Prolactin and GH may, of course, also differ in other sites of action besides the liver. In addition to the somatotropic effects mentioned in the introduction, prolactin has been shown to reduce respiratory (oxygen consumption) metabolism in adult A. carolinensis, especially in the presence of gonadotropins (Licht, 1967). Growth hormone exerts a diabetogenic action in lizards (Penhos et al., 1965). The present results support the earlier conclusion that prolactin has little effect on gonadal activity in the lizards (Licht and Jones, 1967; Licht, 1967). The same appears true of GH.

The diverse sources, means of preparation and purification, and bioassays of the two hormones used here preclude detailed evaluation of their relative potencies. In general, GH was somewhat more effective in promoting growth on the basis of the weight of hormone given.

Bovine GH was clearly effective in promoting growth in Lacerta at a dosage of only $1 \mu \mathrm{g} /$ day, while prolactin was not observed to do so at this concentration. However, these results do not rule out the possibility of a prolactin effect at this concentration. Fortuitously, the dosage of prolactin was increased at the same time that growth rates declined markedly in the controls, the time when the effect of the exogenous hormone may have become distinct. There is cvidenec from inereased food consumption that $1 \mu \mathrm{g}$ of prolactin per day was having some effect in the lizards (Fig. 3) and an acceleration of growth may have just been starting at this time. In any case, prolactin was clearly an effective somatotropic hormone at a dosage of $10 \mu \mathrm{g} /$ day; at $50 \mu \mathrm{g} /$ day it was essentially equal to that of $10 \mu \mathrm{g} /$ day of $\mathrm{GH}$. In previous studies with adult male Anolis, 5-150 $\mu \mathrm{g} /$ day of prolactin promoted a significant increase in growth and $1 \mu \mathrm{g} /$ day of $\mathrm{GH}$ was ineffective in this regard (Licht and Jones, 1967).

The lack of synergism between exogenous GII and prolactin reported here is consistent with the findings in hypophysectomized pigeons (Bates et al., 1962) and intact rats (Bates et al., 1964). Some additive effect between the two hormones might have been expected in the lizard when the lowest concentrations were being used since some response to each hormone was evident between 1 and 10 and between 10 and $50 \mu \mathrm{g} /$ day. Data presented here, particularly with regard to hepatic responses, suggest that GH may antagonize the action of prolactin.

In view of the above considerations, it seems unlikely that the actions of either hormone preparation would be due to contamination from the other hormone. Assuming that the NIH bioassays for the two hormonal activities are adequate for distinguishing them in low concentrations, $1 \mu \mathrm{g}$ GH would contain only 1 milliunit prolactin, which is well under the minimal dosage found to be effective $(1-10 \mu \mathrm{g}$ prolactin was equivalent to $25-250$ milliunits). The minimal effective dosage of ovine prolactin contained between 0.004 and 0.04 milliunits GH activity. In view of the small effect of our lowest dosage of $\mathrm{GH}$ (equivalent to 0.8 milliunits), it seems unlikely that the contamination would account for the response to the prolactin. This conclusion is further supported by the distinctive actions of prolactin and $\mathrm{GH}$.

Further evaluation of the relative importance of prolactin and GH as somatotropic agents in the lizard requires additional information on whether other prolactins, especially the lizards' own, have somatotropic actions in the lizard. Furthermore, assuming that such a somatotropic action exists for the saurian hormone, the relative blood concentrations of endogenous prolactin and growth hormone must be determined. Thus far, the somatotropic effect is the most pronounced action of prolactin demonstrable in the reptiles. 


\section{ACKNOWLEDGMENTS}

We wish to thank Prof. Dr. J. C. van de Kamer for his generosity in providing facilities in the Endocrinology Department in the Zoological Laboratory at Utrecht. We are especially grateful for the hospitality, guidance, and helpful advice of Dr. P. G. W. J. van Oordt in whose laboratories this work was done.

Drs. H. Bern and C. S. Nicoll of the University of California, Berkelcy, offered many helpful suggestions in the preparation of this manuscript. Illustrations were prepared by Miss E. Reed and photographs by Mr. II. van Kooten.

Hormones used in this study were generously supplied by the Endocrinological Study Section of the National Institutes of Health.

This work was supported by a grant from the Lalor Foundation to Paul Licht.

\section{REFERENCES}

Bates, R. W., Miller, R. A., and Garrison, M. M. (1962). Evidence in the hypophysectomized pigeon of a synergism among prolactin, growth hormone, thyroxine and prednisone upon weight of the body, digestive tract, kidney and fat stores. Endocrinology 71, 345-360.
Bates, R. W., Milkovic, S., and Garrison, M. M. (1\%64). Effects of prolactin, growth hormone and ACTH, alone and in combination, upon organ weights and adrenal function in normal rats. Endocrinology 74, 714-723.

Di MAGGio, A., III (1960). Hormonal replacement of photoperiod as a stimulus for growth in a lizard. Federation Proc. 19, Part I. (Abstract).

LICHT, P. (1967). Interaction of prolactin and gonadotropins on appetite, growth, and tail regeneration in the lizard, Anolis carolinensis. Gen. Comp. Endocrinol. 9, 49-63.

Lichт, P., ANd Jones, R. E. (1967). Effeets of exogenous prolactin on reproduction and growth in adult males of the lizard Anolis carolinensis. Gen. Comp. Endocrinol. 8, 228241.

Maderson, P. F. A., and Licht, P. (1967). Epidermal morphology and sloughing frequency in normal and prolactin treated Anolis carolinensis (Iguanidae, Lacertilia). J. Morphol. 123, 157171.

Penhos, J. C., Houssay, B. A., Lujan, M. A. (1965). Total pancreatomy in lizards. Effects of several hormones. Endocrinology 76, 989993. 